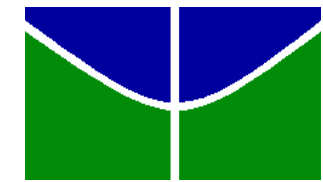

UNIVERSIDADE DE BRASÍLIA

PROGRAMA DE PÓS-GRADUAÇÃO EM AGRONOMIA

FACULDADE DE AGRONOMIA E MEDICINA VETERINÁRIA

\title{
INFLUÊNCIA DO DESPENDOAMENTO E DA ELIMINAÇÃO DE PLANTAS DOMINADAS NA QUALIDADE DE SEMENTES E NA PRODUTIVIDADE DE MILHO
}

CELSO RICARDO POLETTI DIAS

DISSERTAÇÃO DE MESTRADO EM AGRONOMIA

BRASÍLIA, DF

FEVEREIRO/2015 


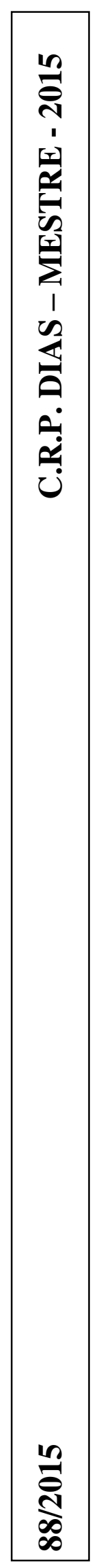




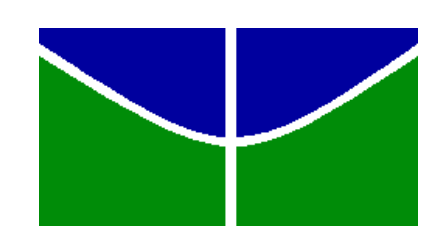

UNIVERSIDADE DE BRASÍLIA

FACULDADE DE AGRONOMIA E MEDICINA VETERINÁRIA PROGRAMA DE PÓS-GRADUAÇÃO EM AGRONOMIA

INFLUÊNCIA DO DESPENDOAMENTO E DA ELIMINAÇÃO DE PLANTAS DOMINADAS NA QUALIDADE DE SEMENTES E NA PRODUTIVIDADE DE MILHO

\section{CELSO RICARDO POLETTI DIAS}

ORIENTADOR: PROF. DR. MARCELO FAGIOLI

CO-ORIENTADORA: PROFa. DRa. NARA OLIVEIRA SILVA SOUZA

DISSERTAÇÃO DE MESTRADO EM AGRONOMIA

PUBLICAÇÃO: 88/2015

BRASÍLIA/DF

FEVEREIRO/2015 


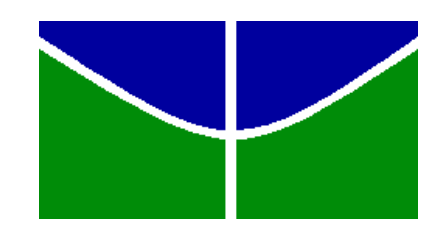

UNIVERSIDADE DE BRASÍLIA

FACULDADE DE AGRONOMIA E MEDICINA VETERINÁRIA

PROGRAMA DE PÓS-GRADUAÇÃO EM AGRONOMIA

\section{INFLUÊNCIA DO DESPENDOAMENTO E DA ELIMINAÇÃO DE PLANTAS DOMINADAS NA QUALIDADE DE SEMENTES E NA PRODUTIVIDADE DE MILHO}

\section{CELSO RICARDO POLETTI DIAS}

Dissertação de Mestrado submetida ao Programa de Pós-Graduação em Agronomia, como parte dos requisitos necessários à obtenção do grau de Mestre em Agronomia (Linha de pesquisa: Sistemas de produção agrícola sustentáveis).

APROVADA POR:

Marcelo Fagioli

D.Sc., Universidade de Brasília, CPF: 729.409.306-78, mfagioli@unb.br Orientador

Carlos Roberto Spehar

Ph.D., Universidade de Brasília, CPF: 122.262.116-91, spehar@unb.br

Examinador Interno

Renato Fernando Amabile

D.Sc., Embrapa Cerrados, CPF: 239.382.421-91, renato.amabile@embrapa.br

Examinador Externo

Brasília, 27 de fevereiro de 2015. 


\title{
FICHA CATALOGRÁFICA
}

\author{
Dias, Celso Ricardo Poletti \\ Influência do despendoamento e da eliminação de \\ plantas dominadas na qualidade de sementes e na produtividade de \\ milho / Celso Ricardo Poletti Dias; orientador Marcelo Fagioli; co- \\ orientador Nara Oliveira Silva Souza. -- Brasília, 2015. \\ $32 \mathrm{p}$. \\ Dissertação (Mestrado em Agronomia) -- Universidade de \\ Brasília/Faculdade de Agronomia e Medicina Veterinária, 2015. \\ 1. Zea Mays L.. 2. Qualidade de sementes. 3. Plantas dominadas. 4. \\ Desfolha. I. Fagioli, Marcelo, orient. II. Souza, Nara Oliveira Silva, co- \\ orient. \\ III. Título.
}

D541i

\section{REFERÊNCIA BIBLIOGRÁFICA}

DIAS, C.R.P. Influência do despendoamento e da eliminação de plantas dominadas na qualidade de sementes e na produtividade de milho. 2015. 32f. Dissertação (Mestrado em Agronomia) - Faculdade de Agronomia e Medicina Veterinária, Universidade de Brasília, Brasília, 2015

\section{CESSÃO DE DIREITOS}

NOME DO AUTOR: Celso Ricardo Poletti Dias

TÍTULO DA DISSERTAÇÃO: Influência do despendoamento e da eliminação de plantas dominadas na qualidade de sementes e na produtividade de milho.

GRAU: Mestre

ANO: 2015

É concedida à Universidade de Brasília permissão para reproduzir cópias dessa dissertação de mestrado para única e exclusivamente propósitos acadêmicos e científicos. $O$ autor reserva para si os outros direitos autorais, de publicação. Nenhuma parte desta dissertação de mestrado pode ser reproduzida sem a autorização por escrito do autor. Citações são estimuladas, desde que citada a fonte.

Celso Ricardo Poletti Dias

CPF: 256.538.958-22

Endereço: Rua Guariroba Qd 23 Lt 5 - Goianésia/GO CEP: 76380-000

Telefone: (62) 9616-1410 Email: celsorpdias@hotmail.com 
A minha amada esposa Ana Paula e ao meu querido filho Pedro.

DEDICO 


\section{AGRADECIMENTOS}

"Todas as vitórias ocultam uma abdicação".

(Simone de Beauvoir)

A Deus pelo dom da vida e a oportunidade de realizar sonhos!

A minha querida esposa Ana Paula pela presença, incentivo, paciência e amor, sempre presente durante todos os momentos da minha vida e, particularmente, para a realização deste momento.

Ao meu filho Pedro pela compreensão nos momentos em que estive ausente.

Ao Dr. Marcelo Fagioli pela orientação, amizade e, principalmente, persistência para a conclusão deste meu curso de mestradol.

A Dra. Nara de Oliveira Silva Souza pelas críticas e sugestões feitas para a redação desta dissertação.

As funcionárias do Laboratório de Análises de Sementes da Limagrain Consuelo Azevedo e Thais Martins pela colaboração nas análises solicitadas.

Ao meu primo Marcus Vinícius pelo apoio logístico e pela amizade oferecida.

Aos meus pais Celso e Maria Helena pela missão de me educar.

A empresa Limagrain pela disponibilidade dos campos de produção e sementes.

A todos que de alguma maneira contribuíram para a realização deste projeto. 


\section{RESUMO}

Dentre os diversos manejos em um campo de produção de sementes de milho híbrido há o despendoamento e a eliminação de plantas dominadas. O objetivo deste trabalho foi verificar o efeito do despendoamento e da eliminação de plantas dominadas na qualidade das sementes e produtividade de milho híbrido. O experimento de despendoamento com diferentes níveis de desfolha foi instalado em três locais com três diferentes genótipos usando o delineamento de blocos ao acaso com três repetições. Cada híbrido foi submetido a eliminação de folhas acima da espiga: 1) retirada total de folhas acima da espiga; 2 ) deixada uma folha acima da espiga; 3) deixada duas folhas acima da espiga; 4) deixada três folhas acima da espiga; 5) deixada quatro folhas acima da espiga; 6) retirada apenas da inflorescência masculina. Os resultados obtidos foram submetidos à análise de variância, seguindose à aplicação do teste de Tukey (5\%) para comparação das médias dos valores de produtividade, germinação, envelhecimento acelerado e peso de 100 sementes. A retirada de um maior número de folhas interfere negativamente na produtividade do campo de produção de sementes de milho híbrido, sendo que a qualidade fisiológica das sementes não é afetada. O experimento de plantas dominadas foi instalado usando o delineamento em blocos ao acaso com três repetições em esquema fatorial $3 \times 2$, sendo três híbridos e dois tipos de plantas (dominadas e dominantes). Das plantas dominadas e dominantes coletaram-se sementes que foram avaliadas por peso e submetidos a testes de germinação e envelhecimento acelerado. Em seguida, uma amostra de sementes foi plantada para avaliar características agronômicas, a ocorrências de plantas dominadas e a produtividade. As médias dos tratamentos foram comparadas pelo teste de Tukey (5\%). A qualidade fisiológica das sementes de plantas dominadas apresenta-se menor comparada com sementes de plantas dominantes. Este fato reflete na maior ocorrência de plantas dominadas e na menor produtividade de grãos por área em plantios com sementes oriundas de plantas dominadas.

Palavras-chave: Zea mays L., qualidade de sementes, plantas dominadas, desfolha. 


\begin{abstract}
Among the various managements in a hybrid corn seed production, have the detasseling and the elimination of dominated plants. The objective of this study was to assess the effect of detasseling and elimination of dominated plants in the quality of seeds and hybrid corn yield. The detasseling experiment with different levels of defoliation was installed at three sites with three different genotypes using the design of a randomized block with three replications. Each hybrid was subjected to removal of leaves above the ear: 1) complete removal of leaves above the ear; 2) left a leaf above the ear; 3) left two leaves above the ear; 4) left three leaves above the ear; 5) left four leaves above the ear; 6 ) withdrawing the male inflorescence only. The results were submitted to analysis of variance, followed by the application of Tukey test $(5 \%)$ to compare the averages of productivity values, germination, accelerated aging and weight of 1000 seeds. The withdrawal of a larger number of leaves negative impact on the productivity of hybrid corn seed production, and the seed quality is not affected. The experiment with dominated plants was installed using randomized complete block design with three replications in a factorial $3 \times 2$, three hybrids and two types of plants (dominated and dominant). The dominated and dominant plants collected up seeds were evaluated by weight and subjected to germination and accelerated aging tests. Then, a seed sample was planted to evaluate the agronomic characteristics, occurrence dominated plants and productivity. The treatment averages were compared by Tukey test (5\%). The physiological quality seeds of dominated plants was lower compared to dominant plant seeds. This reflects the higher incidence of dominated plants and smaller grain yield per area in plantations with seeds produced by plants dominated.
\end{abstract}

Keywords: Zea mays L., quality seeds, dominated plants, defoliation. 


\section{SUMÁRIO}

Página

1. INTRODUÇÃO .....................................................................

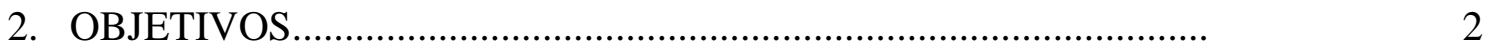

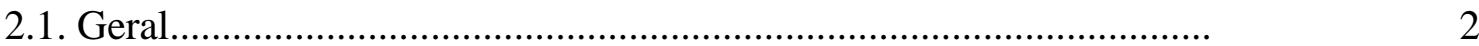

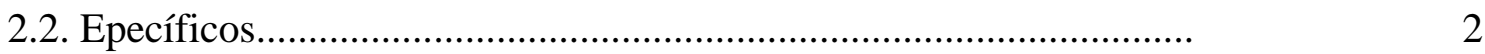

3. REVISÃO BIBLIOGRÁFICA........................................................ 3

3.1. Cultura do milho no Brasil e no mundo........................................... 3

3.2. Morfologia e fisiologia da planta de milho..................................... 3

3.3. Campos de produção de sementes de milho híbrido...........................

3.4. Técnica de despendoamento...........................................................

3.5. Plantas dominadas......................................................................

4. MATERIAL E MÉTODOS.............................................................

4.1. Experimento 1 - Despendoamento de plantas fêmeas....................... 11

4.1.1. Caracterização dos locais e genótipos............................................ 11

4.1.2. Instalação da área experimental e tratamentos................................ 12

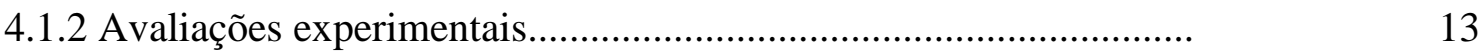

4.1.2.1. Avaliação da qualidade fisiológica............................................. 13

4.1.2.2. Determinação do peso de 1000 sementes....................................... 14

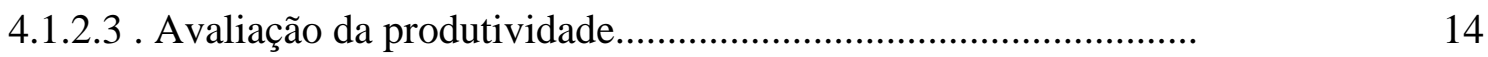

4.1.3. Delineamento e análise estatística................................................ 14

4.2. Experimento 2 - Plantas dominadas.............................................. 15

4.2.1. Caracterização e obtenção de sementes de plantas dominadas...... 15

4.2.2. Localização do experimento........................................................ 16

4.2.3. Instalação da área experimental...................................................... 16

4.2.4. Desenvolvimento do experimento em campo.................................. 16

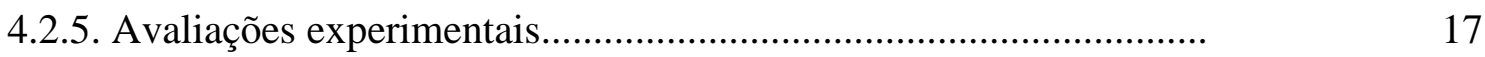

4.2.5.1. Determinação da altura da planta e da espiga............................... 17

4.2.5.2. Determinação do peso de 1000 sementes...................................... 17

4.2.5.3. Avaliação da qualidade fisiológica das sementes....................... 17

4.2.5.4. Avaliação da produtividade...................................................... 18

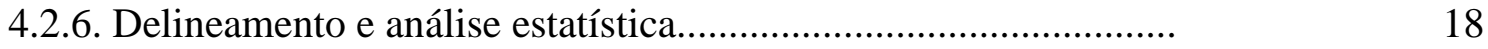


5. RESULTADOS E DISCUSSÃO.................................................. 19

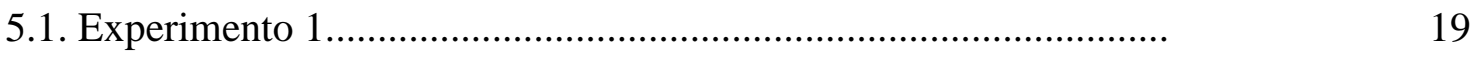

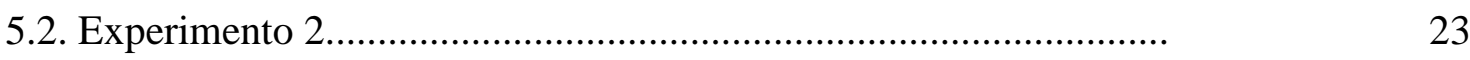

6. CONCLUSÕES..................................................................... 28

6. REFERÊNCIAS................................................................... 29 


\section{INTRODUÇÃO}

O Brasil é o terceiro maior produtor de milho (Zea mays L.) no mundo, com maior concentração de plantio nas regiões Centro Oeste, Sul e Sudeste. O grão é usado para fabricação de óleo, margarina, amido, alimentação in natura e, principalmente, na ração animal. Nos últimos anos houve um aumento da produtividade da cultura, favorecendo inclusive a exportação deste cereal.

O planejamento da produção de sementes híbridas é um dos pontos mais críticos da cultura do milho, pois depende da conexão entre análise da demanda, vendas e definição de preços, para determinar o volume correto a ser produzido. $\mathrm{Na}$ obtenção de sementes de milho híbrido, o cruzamento entre linhagens é bastante sensível às variações ambientais e aos sistemas de manejo da cultura, fatores que podem influenciar a produção e, consequentemente, elevar os custos de produção das sementes. Com o advento do uso da biotecnologia na cultura do milho, há a necessidade de alta eficiência na multiplicação das sementes, elevando a produtividade e a qualidade. A competição do mercado força as empresas de melhoramento a ofertar qualidade com um preço competitivo no mercado.

$\mathrm{Na}$ obtenção de sementes de milho híbrido se faz o despendoamento ou eliminação da inflorescência masculina nas plantas parentais fêmeas. Nesta operação, além da inflorescência masculina, pode ocorrer a eliminação de folhas na planta de milho, sendo influenciado pelo estágio fenológico da planta, a modalidade (manual ou mecânico) e o genótipo. A perda de área foliar decorrente possivelmente alterará a quantidade produzida de sementes do parental feminino.

Outro fator que pode aumentar o custo de produção da semente de milho é a necessidade da eliminação de plantas dominadas no parental fêmea. A importância e a viabilidade desta operação é controversa, pois há um elevado custo envolvido para realiza-la, sem a certeza da eficácia da mesma quanto ao impacto na qualidade da semente. 


\section{OBJETIVOS}

\subsection{Geral}

Verificar o efeito do despendoamento e eliminação de plantas dominadas e seu reflexo na qualidade das sementes e na produtividade de milho.

\subsection{Específicos}

Avaliar o efeito de níveis de desfolha no despendoamento na produtividade da planta fêmea.

Avaliar o efeito de desfolha no despendoamento nas qualidades física e fisiológica das sementes.

Determinar a qualidade física e fisiológica de sementes coletadas de plantas fêmeas dominadas.

Determinar o efeito de sementes oriundas de plantas dominadas sobre as características agronômicas e o aparecimento de plantas dominadas. 


\section{REVISÃO BIBLIOGRÁFICA}

\subsection{Cultura do milho no Brasil e no mundo}

Os primeiros registros do cultivo de milho datam de cerca de 7.300 anos e foram feitos em pequenas ilhas próximas ao litoral mexicano. A cultura se espalhou de forma rápida pelo México. Do Sudoeste do país, onde foi domesticado primeiro, o milho foi levado para o Sudeste mexicano e para outras regiões tropicais da América, como o Panamá e a América do Sul (EMBRAPA, 2014).

O Brasil ocupa o terceiro lugar na produção mundial de grãos de milho, colhendo 81,5 milhões de toneladas na safra 2012/2013, sendo superado apenas pelos Estados Unidos e pela China (USDA, 2014).

Segundo a CONAB (2015), foram plantados 15420,6 mil hectares no Brasil, tendo como principal estado em área de plantio o Mato Grosso com 3420,9 mil hectares, seguido do Paraná com 2842,7 mil hectares plantados. Em relação a produtividade destaca-se o Distrito Federal com uma média de $9378 \mathrm{~kg} \mathrm{ha}^{-1}$, associada a grande proporção de áreas irrigadas. Outro dado interessante é a grande diferença em produtividade entre a região Centro Sul, com média de $5691 \mathrm{~kg} \mathrm{ha}^{-1}$, e o Norte/Nordeste, com $2564 \mathrm{~kg} \mathrm{ha}^{-1}$. Esta diferença é explicada pelas diferentes tecnologias empregadas no manejo da cultura. No Centro Sul predominam cultivos em grandes áreas, com uso de defensivos agrícolas e altamente mecanizados, enquanto no Norte/Nordeste se concentra em pequenas áreas e com baixo uso de tecnologia, dependendo de mão-de-obra desde o plantio até a colheita.

\subsection{Morfologia e fisiologia da planta de milho}

O milho é uma planta anual, monocotiledônea, de fisiologia $\mathrm{C} 4$ e pertencente à classe Monocotyledoneae, família Poacea, gênero Zea, espécie Zea mays (L.). Morfologicamente a planta de milho é constituída por um colmo cilíndrico ereto, de 1 a $4 \mathrm{~m}$ de altura, formada por nós e entrenós, apresentando inflorescências femininas (espigas) e masculinas (pendão ou flecha), além de folhas lanceoladas, devidamente suportadas por um sistema radicular fasciculado (FANCELLI; DOURADO NETO, 2000).

O milho, é uma espécie monóica, com flores masculinas e femininas na mesma planta, porém em estruturas reprodutivas distintas denominadas inflorescências. As 
flores masculinas encontram-se dispostas em panículas, terminais ao colmo, sendo designadas por pendão ou flecha. As flores femininas encontram-se inseridas em inflorescências, do tipo espiga, localizadas na porção mediana da planta, entre o $6^{\circ} \mathrm{e}$ 9ํós (FANCELLI; DOURADO NETO, 2000).

O milho é uma das mais eficientes plantas armazenadoras de energia existentes na natureza. De uma semente que pesa pouco mais de $0,3 \mathrm{~g}$ irá surgir uma planta com mais de 2,0 $\mathrm{m}$ de altura, em cerca de nove semanas. Na fase reprodutiva, essa planta produz cerca de 600 a 1000 sementes similares àquela da qual se originou (ALDRICH et al., 1982).

Para o manejo da cultura e estudo de correlações entre elementos fisiológicos, climatológicos, fitogenéticos, entomológicos, fitopatológicos e fitotécnicos com o desempenho da planta, o ciclo da cultura do milho foi dividido em 11 estádios distintos de desenvolvimento, de acordo com a escala proposta por Fancelli (1986) e adaptada de Nel e Smit (1978) e Hanaway (1982), conforme Figura 1.

\subsection{Campos de produção de sementes de milho híbrido}

As características morfológicas da planta do milho permitem o uso da hibridação como método de melhoramento, aliado às relativas facilidades de produção de sementes explorando níveis heteróticos apreciáveis (PATERNIANI; CAMPOS, 1999).

Segundo Culy et al. (1991), a produção de híbridos demanda o desenvolvimento de linhagens para realização dos cruzamentos; a linhagem utilizada como fornecedora de pólen é chamada de macho ou polinizador, enquanto a receptora de pólen e que terá a espiga colhida é considerada fêmea. A distribuição uniforme de pólen às plantas fêmeas requer alternância no plantio de entrelinhas de fêmeas e de polinizadores, de modo a maximizar o rendimento do campo de produção de sementes. Os parentais podem ser semeados em épocas distintas, para assegurar a coincidência dos ciclos das linhagens no florescimento. Após a polinização, as linhas de polinizadores são destruídas para prevenir mistura de espigas entre os parentais durante a colheita. 


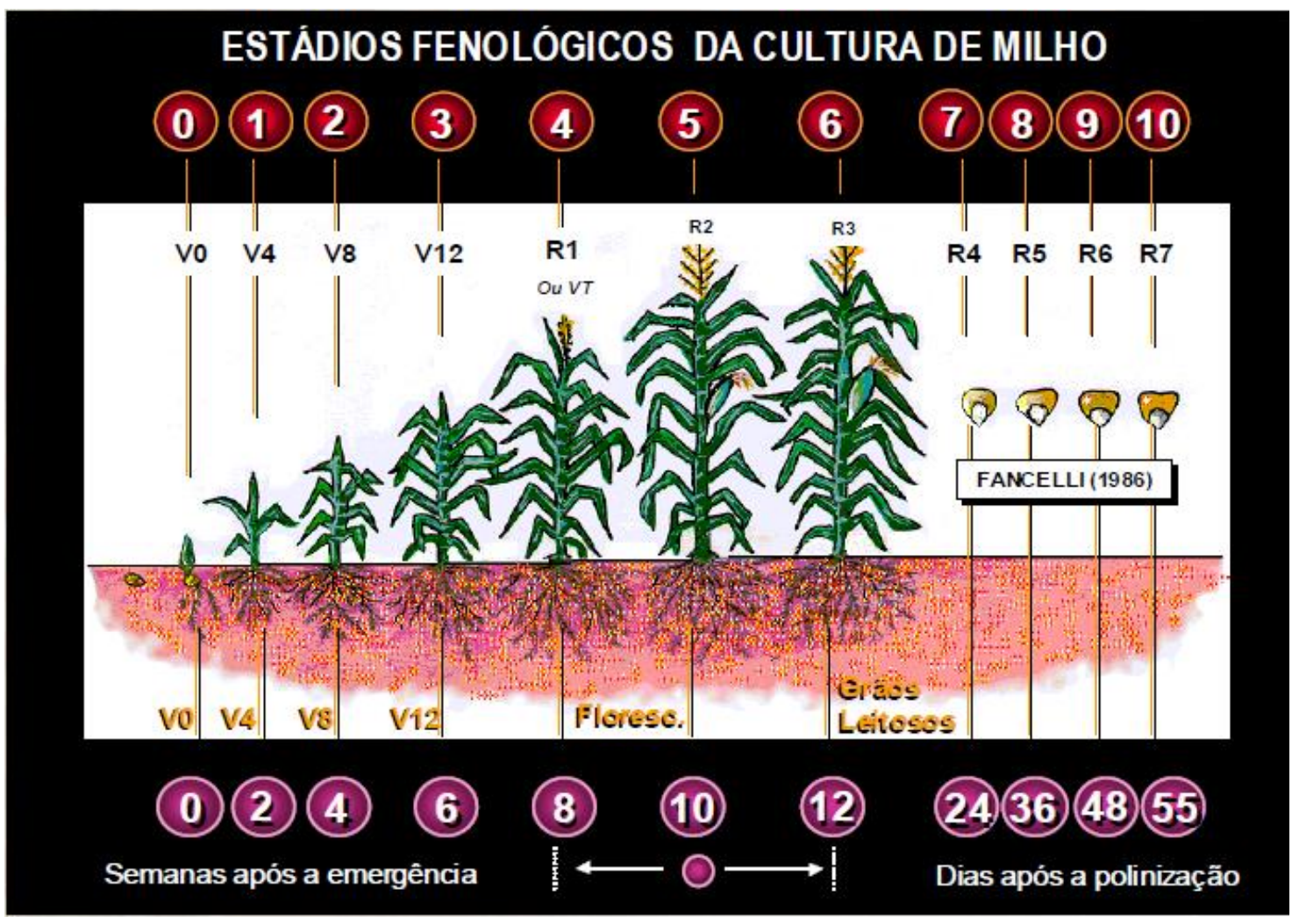

Figura 1. Ciclo de cultura: estádios fenológicos (Fancelli, 1986) adaptado de Nel e Smit, 1978 e Hanaway, 1982).

\subsection{Técnica de despendoamento}

As folhas, inseridas nas várias posições do caule, contribuem diferencialmente no suprimento de metabólitos para as demais partes da planta. Em geral, as raízes recebem produtos fotossintetizados, principalmente das folhas mais basais, enquanto que os órgãos e tecidos, localizados na parte apical, são alimentados pelas folhas mais superiores. Do total de carboidratos acumulados nos grãos de milho, $50 \%$ são produzidos pelas folhas localizadas no terço superior da planta, $30 \%$ representa a contribuição das folhas do terço médio e o restante das folhas distribuídas na parte mais basal do colmo (FORNASIERI-FILHO, 1992).

No processo de despendoamento, quer seja manual ou mecanizado, ocorre a remoção de folhas do ápice, junto ao pendão, o que poderá provocar redução da produtividade e da qualidade das sementes. Embora existam comprovações de perdas relacionadas ao despendoamento, com a utilização de máquinas (McDONALD; COPELAND, 1996), as informações para as condições brasileiras são escassas. 
Historicamente os campos de produção de sementes de milho híbrido eram despendoados manualmente. Com a escassez de mão-de-obra qualificada e o consequente aumento no custo, em especial em campos com certa desuniformidade, as companhias produtoras de sementes de milho híbrido tem substituído o despendoamento manual pelo mecanizado (KOMATUDA et al., 2006).

Magalhães et al. (1999), simulando despendoamento mecânico, utilizaram tesoura para efetuar o corte manual do pendão a uma altura pré-determinada das plantas. Foi verificado que tal causou perdas de folhas e afetou a produção de sementes, reduzindo em torno de $9 \%$. Porém, tal procedimento difere do despendoamento efetuado com máquina apropriada para esse fim. Portanto, estudos que quantifiquem perdas de produtividade e de qualidade das sementes nos campos de produção de milho híbrido submetido ao despendoamento mecanizado, são importantes.

Despendoar pode favorecer ou prejudicar a planta, dependendo do método utilizado. Por exemplo, a retirada apenas do pendão, que é um forte dreno, pode favorecer a planta, uma vez que diminui a concorrência por fotoassimilados. Porém sua remoção pode resultar em prejuízo à planta, porque normalmente ocorre uma perda de folhas superiores. O balanceamento da relação fonte/dreno em milho é dependente da área foliar, pois um desequilíbrio nessa relação pode afetar diretamente a produção de grãos. Assim, limitações no rendimento de milho não são explicadas por fatores desfavoráveis tais como pragas, doenças, teor de nutrientes no solo e estresse hídrico podem ser analisadas em termos do suprimento de fotoassimilados (fonte) para os grãos e o potencial dos grãos (dreno) em acomodar estes fotoassimilados (TOLLENAAR, 1977).

Fancelli (1988) ressaltou que, além da queda de produtividade, a qualidade fisiológica das sementes foi afetada resultando em redução do poder germinativo quando do arranquio de folhas na planta de milho.

A fotossíntese realizada pelos tecidos que formam a espiga mostrou contribuir com pouco efeito na reposição de material nos grãos em virtude de sua área reduzida fotossintetizadora (FANCELLI; DOURADO NETO, 2000).

Segundo Jugenheimer (1976) os genitores femininos que melhor se adaptam ao despendoamento mecanizado são aqueles com uniformidade de altura de plantas e cuja emergência do pendão ocorre antes da liberação dos grãos de pólen. Na prática 
essa sincronia nem sempre ocorre e o despendoamento mecanizado necessita complementação manual na remoção de falhas e de pendões de maturação tardia, garantindo, assim, a pureza genética das sementes híbridas.

O número de folhas removidas com o pendão dependerá da morfologia da planta, da época do despendoamento em relação à época da emergência do pendão, da liberação de pólen, da emergência dos estilos-estigma e da regulagem da máquina, no caso do despendoamento mecanizado (WILHELM et al., 1995).

Aproximadamente metade dos grãos da ponta da espiga não se desenvolveram sob condições de desfolha, e os grãos que completaram o desenvolvimento ficaram mais leves que os produzidos pela testemunha não desfolhada. O estresse na planta como resultado de desfolha, refletiu diretamente no peso de grãos, isso evidencia que qualquer forma de estresse nesse estádio de desenvolvimento pode afetar esse componente de rendimento. Assim, estresse no período de 15 dias após o florescimento, por causa ambiental ou prática cultural, pode reduzir a produção significativamente em função do decréscimo em número e peso de grãos (EGHAREVBA et al., 1976).

A desfolha não afetou a taxa de enchimento de grãos, porém reduziu o número de grãos por espiga (PRIOUL; SCHWEBEL-DUGUÉ,1992). De acordo com Wang et al. (1998) a duração do período efetivo de enchimento de grãos e o número de grãos mostraram correlação com a produção individual da planta.

A qualidade fisiológica, avaliada por testes de germinação, de frio e de envelhecimento acelerado, não foi afetada devido à remoção de folhas durante o despendoamento (WILHELM et al., 1995). Hunter e Tekrony (1988) obtiveram resultados semelhantes, sugerindo que a qualidade fisiológica das sementes está mais relacionada com a maturidade na colheita do que com a desfolha.

Komatuda et al. (2006) verificaram que a germinação e o vigor das sementes de milho com formato redondo não foram alterados pelos métodos de despendoamentos empregados.

Frascaroli et al. (2005) observaram variação genética em tolerância ao frio e na reação de desfolha aplicada durante o período de maturação. As sementes de progênie $\mathrm{F} 1$ de híbrido simples colhida de plantas desfolhadas apresentaram elevada germinação no teste de frio, no mesmo estádio de desenvolvimento de sementes colhidas de plantas não desfolhadas. A aceleração da maturação fisiológica das 
sementes devido à desfolha não reduziu o seu vigor. Desse modo, a expressão máxima de vigor das sementes está fortemente associada à maturidade fisiológica, como expressada pela formação da camada negra tanto em plantas desfolhadas como intactas, independente dos genótipos. Os autores verificaram que o tamanho das sementes ficou reduzido no ano em que ocorreram desfolha e temperaturas elevadas; entretanto, o vigor máximo das sementes não reduziu para linhagens, híbridos simples e híbridos duplos.

Tollenaar et al. (2004) afirmaram que o máximo índice de área foliar (IAF) é função, em especial, do tamanho e não do número total de folhas.

Magalhães et al. (1999) testaram diferentes métodos de despendoamento em milho tropical, quantificando possíveis perdas ou ganhos decorrentes do uso dessas técnicas. concluíram que num campo de produção de sementes híbridas de milho o despendoamento manual ou o uso da macho-esterilidade são as práticas mais recomendadas para o controle da polinização e que o uso da retirada do cartucho, que visa assegurar a pureza genética, afeta negativamente a produção de sementes em cerca de $10 \%$.

\subsection{Plantas dominadas}

A capacidade de germinação de um lote de sementes é determinada pela proporção das sementes que podem produzir plântulas normais em condições favoráveis. Na ausência de condições favoráveis, observa-se normalmente uma redução na porcentagem de germinação. Fatores que pode afetar o vigor são: o genético, durante a produção, danos mecânicos, condições ambientais durante o armazenamento, densidade e tamanho de sementes, idade da semente, baixas temperaturas durante a embebição, microorganismos e insetos (CARVALHO; NAKAGAWA, 2000).

A distribuição dos fotoassimilados para as estruturas reprodutivas parece ser prejudicada nos indivíduos dominados, independentemente do nível de competição, como elevada densidade populacional, porque eles tiveram um reduzido número de sementes por planta comparado com os indivíduos de plantas dominantes em todas as taxas de crescimento da planta (MADDONNI; OTEGUI, 2004).

$O$ elevado potencial produtivo do milho pode ser afetado pela competição intraespecífica e interespecífica. A uniformidade no desenvolvimento fenológico das 
plantas na lavoura tem direto impacto no aproveitamento dos recursos do ambiente e no rendimento. Em lavouras com emergência uniforme, as plantas são mais homogêneas quanto à sua arquitetura, minimizando a competição intraespecífica (SANGOI et al., 2010).

A desuniformidade entre plantas na lavoura de milho é uma característica indesejada por técnicos e produtores. Dentre as causas destacam-se a utilização de sementes com baixo poder germinativo e/ou com variabilidade no tamanho e forma, a presença de solos compactados, com baixa temperatura, umidade deficiente, além das velocidades excessivas do trator durante a semeadura. Os prejuízos da desuniformidade na emergência são maiores quando se trabalha com altas densidades e espaçamentos amplos entre linhas, fatores que acentuam a competição intraespecífica (MADDONNI; OTEGUI, 2004).

Schenatto et al. (2012) demonstraram que o aumento da desuniformidade na emergência de plantas na linha de semeadura reduz o rendimento de grãos do milho, principalmente quando o mesmo é cultivado em espaçamentos maiores entre linhas.

O uso de sementes com variação no vigor resulta em maior competição intraespecífica devido à menor capacidade competitiva das plantas menos vigorosas, sendo estas dominadas pelas originadas de alto vigor, refletindo negativamente em produção por planta (MONDO, 2009).

Os efeitos da competição entre plantas são mais evidentes quando as plantas estão em maior população ou quando são dominadas por plantas vizinhas de emergência mais rápida. Além disso, as plântulas com emergência atrasada podem apresentar menor crescimento da parte aérea e do sistema radicular, resultando em menor capacidade de competição por água, luz e nutrientes (MEROTTO JÚNIOR et al., 1999).

A desuniformidade na velocidade de emergência afeta o desenvolvimento do dossel da cultura, sendo que plântulas que emergem primeiro sombreaiam as plântulas com emergência mais tardia (POMMEL et al., 2002). O menor vigor reduz a velocidade de emergência, pois antes do início do crescimento do eixo embrionário demandam tempo para restauração de organelas e tecidos danificados (VILLIERS, 1973).

Quando não há redução significativa na densidade inicial, não é esperada influência do potencial fisiológico das sementes sobre a produtividade final, para as 
plantas produtoras de grãos, no entanto, na competição por recursos dentro das populações de plantas (cultura), o rápido crescimento da parte aérea e sistema radicular serão decisivos para o futuro do indivíduo, pois é durante a fase de crescimento que se manifestam as características de plasticidade fenotípica e, sobretudo, as ações modificativas em relação às condições do habitat (LARCHER, 2000).

O aparecimento de plantas dominadas pode interferir na sincronia de liberação do pólen e na presença do estilo-estigma receptivo (pelas plantas fêmeas) em campos de produção de sementes de milho (PAGANO et al., 2007). 


\section{MATERIAL E MÉTODOS}

Os genótipos (linhagens, híbridos simples e híbridos triplos) utilizados neste experimento são pertencentes à empresa Limagrain ${ }^{\circledR}$ e foram codificados para atender a política de segurança intelectual da empresa. Os genótipos tiveram origem de campos de produção de sementes de milho híbrido inscritos no MAPA.

\subsection{Experimento 1 - Despendoamento de plantas fêmeas}

\subsubsection{Caracterização dos locais e genótipos}

O experimento foi realizado com três genótipos em três locais representativos da produção de milho na região do Cerrado.

Um dos genótipos estudados foi a linhagem L1 que é usada como parental fêmea do híbrido simples comercial HS1. O local do experimento foi na Fazenda Carapinas, em Paracatu-MG, nas coordenadas de 16 49' 32,4" Sul, 46 59' 32,3" Oeste e altitude de $856 \mathrm{~m}$. Anteriormente à instalação do experimento, realizou-se coleta de amostra de solo para análise química cujos resultados foram: $\mathrm{pH}$ em $\mathrm{CaCL}_{2}=$ 6,0; M.O. $=39 \mathrm{~g} \mathrm{dm}^{-3} ; \mathrm{P}($ resina $)=19 \mathrm{mg} \mathrm{dm}^{-3} ; \mathrm{Al}^{+3}=1 \mathrm{mmol}_{\mathrm{c}} \mathrm{dm}^{-3} ; \mathrm{H}+\mathrm{Al}=38 \mathrm{mmol}_{\mathrm{c}}$ $\mathrm{dm}^{-3} ; \mathrm{K}=2,7 \mathrm{mmol}_{\mathrm{c}} \mathrm{dm}^{-3} ; \mathrm{Ca}=30 \mathrm{mmol}_{\mathrm{c}} \mathrm{dm}^{-3} ; \mathrm{Mg}=14 \mathrm{mmol}_{\mathrm{c}} \mathrm{dm}^{-3}$. A calagem foi realizada dois meses antes da semeadura para elevação da saturação por bases. Anteriormente ao plantio do milho foi conduzida a cultura da abóbora híbrida.

Outro genótipo avaliado foi a linhagem L2 usada como parental fêmea do híbrido simples comercial HS2. O local foi na Fazenda Santiago, em Vianópolis-GO, nas coordenadas de $16^{\circ} 51^{\prime} 12,1^{\prime \prime} \mathrm{Sul}, 48^{\circ} 28^{\prime}$ 27,4" Oeste e altitude de $911 \mathrm{~m}$. A análise química do solo apresentou os seguintes resultados: $\mathrm{pH} \mathrm{em} \mathrm{CaCl}_{2}=5,9 ; \mathrm{M}$.O. $=24 \mathrm{~g} \mathrm{dm}^{-3} ; \mathrm{P}($ resina $)=18 \mathrm{mg} \mathrm{dm}^{-3} ; \mathrm{Al}^{+3}=3 \mathrm{mmol}_{\mathrm{c}} \mathrm{dm}^{-3} ; \mathrm{H}+\mathrm{Al}=48 \mathrm{mmol}_{\mathrm{c}} \mathrm{dm}^{-3}$; $\mathrm{K}=1,7 \mathrm{mmol}_{\mathrm{c}} \mathrm{dm}^{-3} ; \mathrm{Ca}=25 \mathrm{mmol}_{\mathrm{c}} \mathrm{dm}^{-3} ; \mathrm{Mg}=12 \mathrm{mmol}_{\mathrm{c}} \mathrm{dm}^{-3}$. A calagem foi realizada três meses antes da semeadura para elevação da saturação por bases. A cultura instalada anteriormente foi feijão.

O terceiro genótipo usado foi o híbrido simples HS3 usado como parental fêmea do híbrido triplo comercial HT3. O local foi na Fazenda Piscamba, em Cristalina-GO, nas coordenadas de $16^{\circ} 48^{\prime} 00,1^{\prime \prime}$ Sul, 47 $14^{\circ}$ 06,2" Oeste e altitude de $903 \mathrm{~m}$. Antes do plantio do campo de milho havia a cultura do feijão. A análise de solo apresentou os seguintes resultados: $\mathrm{pH} \mathrm{em} \mathrm{CaCl}_{2}=6,3 ; \mathrm{M} . \mathrm{O}=44 \mathrm{~g} \mathrm{dm}^{-3} ; \mathrm{P}($ resina $)=20 \mathrm{mg} \mathrm{dm}^{-3}$; 
$\mathrm{Al}^{+3}=1 \mathrm{mmol}_{\mathrm{c}} \mathrm{dm}^{-3} ; \mathrm{H}+\mathrm{Al}=40 \mathrm{mmol}_{\mathrm{c}} \mathrm{dm}^{-3} ; \mathrm{K}=2,9 \mathrm{mmol}_{\mathrm{c}} \mathrm{dm}^{-3} ; \mathrm{Ca}=40 \mathrm{mmol}_{\mathrm{c}} \mathrm{dm}^{-3} ;$ $\mathrm{Mg}=13 \mathrm{mmol}_{\mathrm{c}} \mathrm{dm}^{-3}$.

Nos três locais o solo foi classificado como Latossolo Vermelho Amarelo (EMBRAPA, 2006) e são parte do domínio morfoclimático do Cerrado, e apresenta, de acordo com Köppen e Geiger (1928), clima tropical estacional de savana, com inverno seco e verão chuvoso. A precipitação média anual oscila entre $1400 \mathrm{~mm}$ e $1600 \mathrm{~mm}$ e a temperatura média do ar anual varia de $22^{\circ} \mathrm{C}$ a $27^{\circ} \mathrm{C}$ (ADÁMOLI et al., 1987).

As áreas de produção dos campos de sementes foram instaladas sob cultivo irrigado por pivô central, sendo obrigatório esta modalidade na produção de sementes de milho híbrido da empresa Limagrain ${ }^{\circledR}$.

\subsubsection{Instalação da área experimental e tratamentos}

As datas de plantio dos campos de produção e da instalação dos experimentos estão apresentadas no Quadro 1.

Quadro 1. Local, genótipo, data de plantio do campo de produção e data de instalação dos experimentos.

\begin{tabular}{|c|c|c|c|}
\hline LOCAL & GENÓTIPO & $\begin{array}{c}\text { DATA DE } \\
\text { PLANTIO }\end{array}$ & $\begin{array}{c}\text { DATA DE } \\
\text { INSTALAÇÃO }\end{array}$ \\
\hline Paracatu & L1 & $10 / 09 / 2013$ & $10 / 11 / 2013$ \\
\hline Vianópolis & L2 & $15 / 11 / 2013$ & $13 / 01 / 2014$ \\
\hline Cristalina & HS3 & $12 / 09 / 2013$ & $15 / 11 / 2013$ \\
\hline
\end{tabular}

As parcelas foram constituídas por quatro linhas cada, com cinco metros de comprimento, e espaçamento de $0,70 \mathrm{~m}$ nas entrelinhas, totalizando $14 \mathrm{~m}^{2}$ Foi considerada área útil de $5,6 \mathrm{~m}^{2}$ das duas linhas centrais de cada parcela, desprezando $0,50 \mathrm{~m}$ de cada extremidade.

Foi feita a adubação na linha de plantio com $500 \mathrm{~kg} \mathrm{ha}^{-1}$ da fórmula NPK 0828-16, $300 \mathrm{~kg} \mathrm{ha}^{-1}$ de uréia em duas aplicações de cobertura e $100 \mathrm{~kg} \mathrm{ha}^{-1}$ de $\mathrm{KCl}$. $\mathrm{O}$ controle de plantas invasoras foi feito em pré emergência das ervas com a utilização de $1080 \mathrm{~g} \mathrm{ha}^{-1}$ do i.a. Metolachor e $2000 \mathrm{~g} \mathrm{ha}^{-1}$ do i.a. Atrazine com 20 dias de emergência da cultura. Para o controle da Spodoptera frugiperda foi utilizado produto formulado com ingrediente ativo Spinosad, na dose de $25 \mathrm{~g} \mathrm{ha}^{-1}$.

A retirada da inflorescência masculina do parental fêmea foi realizada manualmente, no estádio fenológico V8, sendo o delineamento experimental e os 
tratamentos aplicados. Os tratamentos adotados foram: 1) retirada total de folhas acima da espiga; 2) deixada uma folha acima da espiga; 3) deixada duas folhas acima da espiga; 4) deixada três folhas acima da espiga; 5) deixada quatro folhas acima da espiga; 6) retirada apenas da inflorescência masculina. A Figura 2 mostra a operação de despendoamento realizada pelo trabalhador rural.

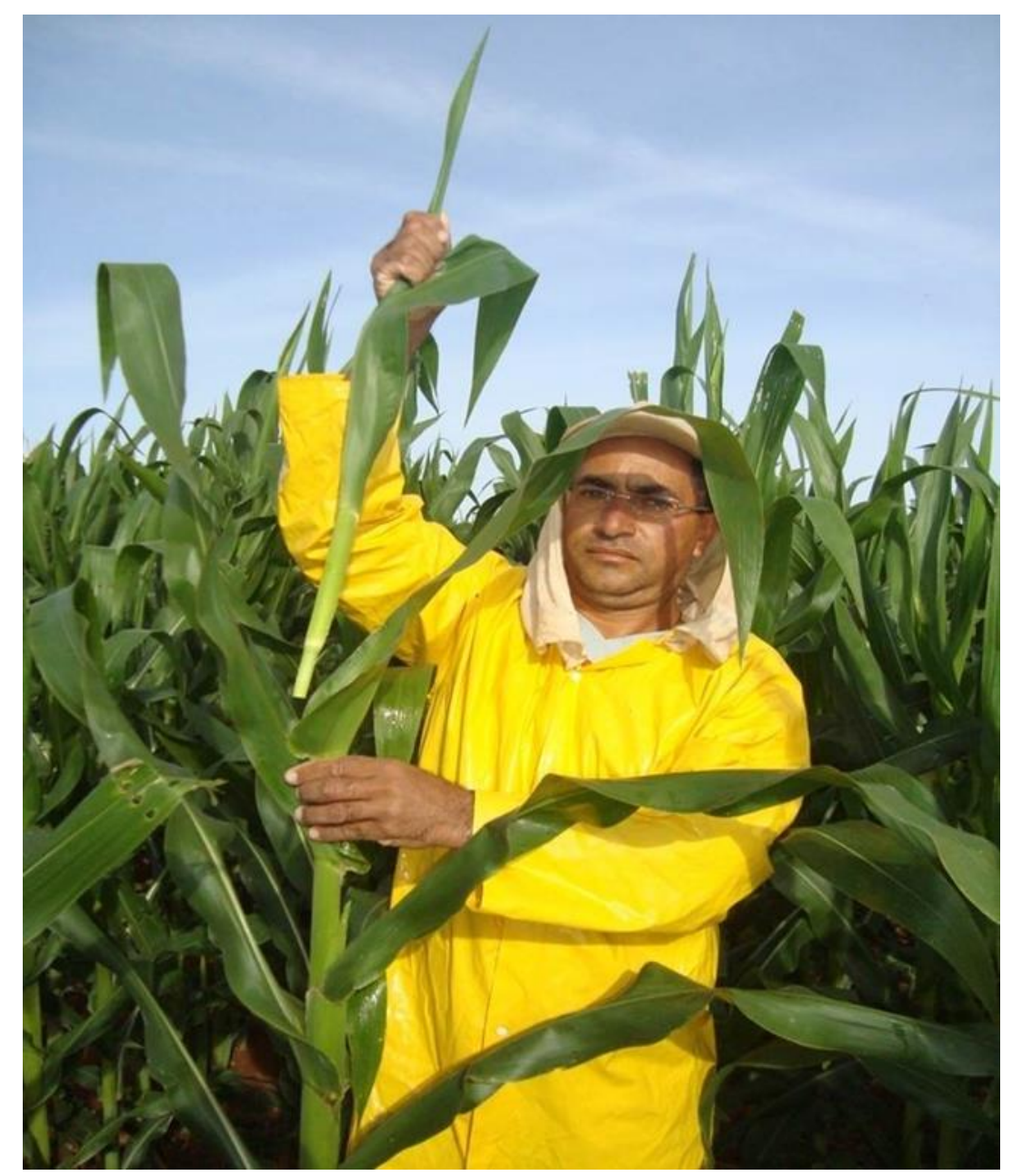

Figura 2. Despendoamento da planta de milho.

\subsubsection{Avaliações experimentais}

\subsubsection{Avaliação da qualidade fisiológica}

Para a avaliação fisiológica das sementes foram feitos os testes de germinação e de envelhecimento acelerado no Laboratório de Análise de Sementes da Limagrain $^{\circledR}$, em Goianésia-GO. 


\section{a) Teste de germinação}

O teste de germinação foi realizado com quatro repetições de 50 sementes por tratamento, em rolo de papel toalha, tipo Germitest, embebido em água na quantidade de 2,5 vezes o peso do substrato seco, acondicionado em sacos plásticos. Foram mantidos em câmara de germinação, à temperatura de $25^{\circ} \mathrm{C}$, sendo a contagem das plântulas normais feitas no quinto dia, seguindo-se os critérios estabelecidos nas Regras para Análise de Sementes (BRASIL, 2009). Os resultados foram expressos em porcentagem média de plântulas normais.

b) Teste de envelhecimento acelerado

As sementes foram distribuídas em camada única sobre uma tela metálica que foi encaixada dentro de uma caixa plástica para germinação $(11,0 \times 11,0 \times 3,5 \mathrm{~cm})$, contendo $40 \mathrm{~mL}$ de água destilada no fundo e foi mantida em câmara de germinação, a $42{ }^{\circ} \mathrm{C}$ por $48 \mathrm{~h}$ (MARCOS FILHO, 1999). Após o período de envelhecimento, as sementes foram submetidas ao teste de germinação, realizando-se a contagem de plântulas normais no quinto dia (BRASIL, 2009).

\subsubsection{Determinação do peso de 1000 sementes}

O peso de 1000 sementes (P1000), foi obtido pela média da contagem e pesagem de oito repetições de 100 sementes. $O$ resultado foi expresso em gramas, conforme as Regras para Análise de Sementes - RAS (BRASIL, 2009).

\subsubsection{Avaliação da produtividade}

Foi obtida a produtividade de cada parcela através da colheita manual das espigas na área útil, com um teor de água entre 30\% e 32\%, sendo secas em câmaras de secagem de milho em espiga, na Unidade de Beneficiamento de Sementes da empresa Sempre Sementes, em Santa Helena de Goiás-GO, até atingirem a umidade de $12 \%$. Foi feita a debulha das espigas e obtido o peso dos grãos de cada parcela, expressos em $\mathrm{kg}$.

\subsubsection{Delineamento e análise estatística}

Foi usado o delineamento de blocos ao acaso com 3 repetições. Os resultados obtidos foram submetidos à análise de variância (SILVA, 2014), seguindo-se à 
aplicação do teste de Tukey $(P \leq 0,05)$ para comparação das médias dos valores de produtividade, germinação, envelhecimento acelerado e peso de 1000 sementes.

\subsection{Experimento 2 - Plantas dominadas}

\subsubsection{Caracterização e obtenção de sementes de plantas dominadas}

As plantas dominadas foram consideradas sendo de uma altura inferior a $70 \%$ da altura média das plantas do parental fêmea no estádio fenológico R7 do campo de produção. A Figura 3 mostra uma planta normal comparada a duas plantas dominadas.

Foram coletadas sementes oriundas de três diferentes genótipos de plantas dominadas de parentais fêmeas em três campos de produção. O híbrido simples HS4 foi obtido na Fazenda Madeira do Mocambo, em Gameleira de Goiás-GO. Na Fazenda Carapinas, em Paracatu-MG, foi obtido o híbrido triplo HT5. O híbrido duplo HD6 foi obtido na Fazenda São Carlos, no município de São Luiz do Norte-GO.

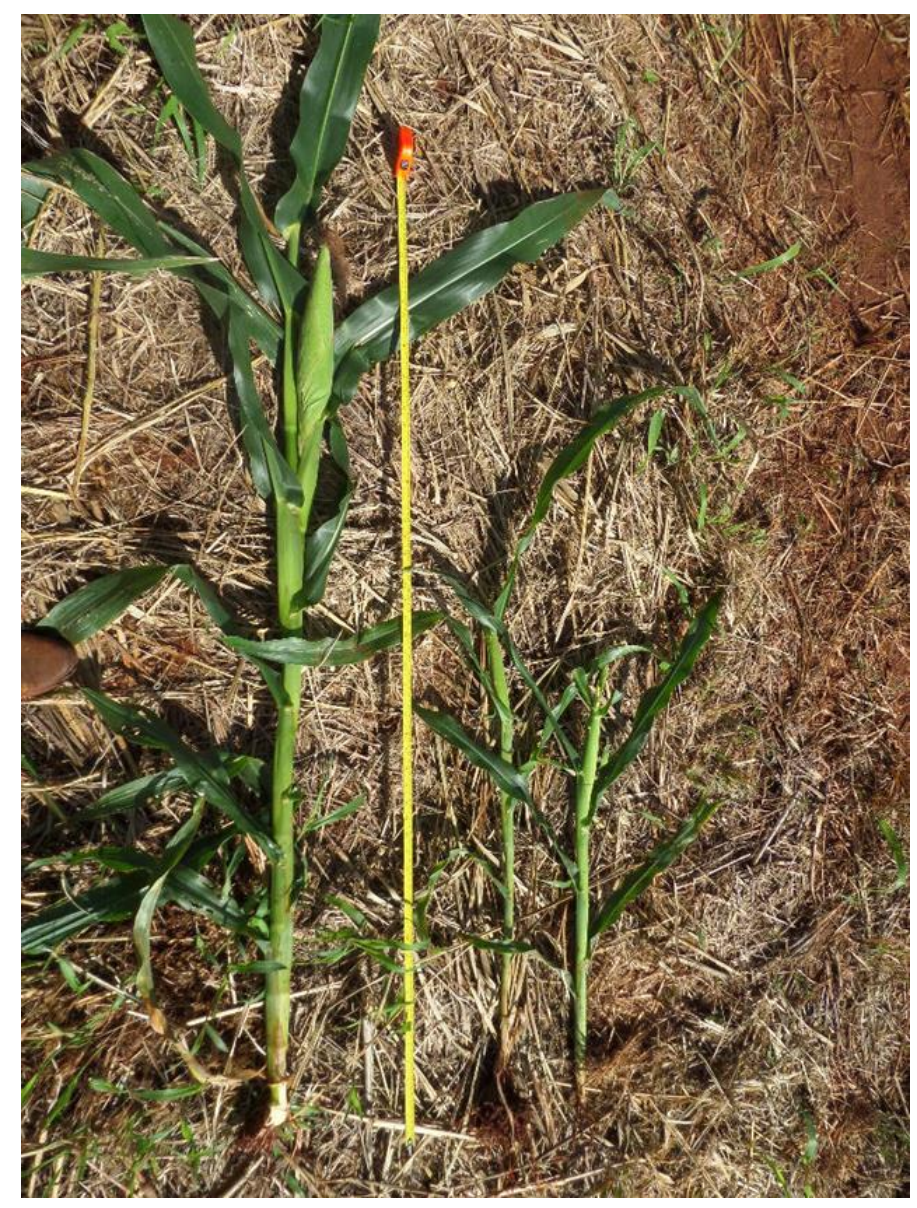

Figura 3. Planta normal dominante (esquerda) e plantas dominadas 


\subsubsection{Localização do experimento}

O experimento foi instalado na Fazenda Laguna, no município de Barro AltoGO, nas coordenadas de $14^{\circ} 54^{\prime} 46,7^{\prime \prime}$ Sul, $48^{\circ} 54^{\prime} 33,0^{\prime \prime}$ Oeste, altitude $660 \mathrm{~m}$. O solo é um Latossolo Vermelho (EMBRAPA, 2006).

A área é parte do domínio morfoclimático do Cerrado, e apresenta, de acordo com Köppen e Geiger (1928), clima tropical estacional de savana, com inverno seco e verão chuvoso. A precipitação média anual oscila entre $1400 \mathrm{~mm}$ e $1600 \mathrm{~mm}$ e a temperatura média anual varia de $22^{\circ} \mathrm{C}$ a $27^{\circ} \mathrm{C}$ (ADÁMOLI et al., 1987).

Dois meses antes do plantio foi feita a análise de solo apresentando os seguintes resultados: $\mathrm{pH}$ em $\mathrm{CaCl}_{2}=6,2 ; \mathrm{M} . \mathrm{O} .=29 \mathrm{~g} \mathrm{dm}^{-3} ; \mathrm{P}($ resina $)=23 \mathrm{mg} \mathrm{dm}^{-3}$; $\mathrm{Al}^{+3}=0 \mathrm{mmol}_{\mathrm{c}} \mathrm{dm}^{-3} ; \mathrm{H}+\mathrm{Al}=18 \mathrm{mmol}_{\mathrm{c}} \mathrm{dm}^{-3} ; \mathrm{K}=1,5 \mathrm{mmol}_{\mathrm{c}} \mathrm{dm}^{-3} ; \mathrm{Ca}=33 \mathrm{mmol}_{\mathrm{c}} \mathrm{dm}^{-3}$; $\mathrm{Mg}=19 \mathrm{mmol}_{\mathrm{c}} \mathrm{dm}^{-3}$.

\subsubsection{Instalação da área experimental}

O experimento foi instalado em janeiro de 2014, após a colheita da soja em uma área irrigada pelo sistema de irrigação por aspersão móvel (pivô central).

As parcelas foram constituídas por quatro linhas cada, com cinco metros de comprimento, e espaçamento de $0,70 \mathrm{~m}$ nas entrelinhas, totalizando $14 \mathrm{~m}^{2}$. Foi considerada área útil de $5,6 \mathrm{~m}^{2}$ das duas linhas centrais, menos $0,50 \mathrm{~m}$ da extremidade de cada linha.

\subsubsection{Desenvolvimento do experimento em campo}

Além das sementes colhidas de plantas dominadas dos três genótipos (HS4, HT5 e HD6), foram também colhidas sementes de plantas não dominadas (plantas dominantes) para a condução do experimento.

A população foi de 65000 plantas ha-1 com adubação de plantio de $400 \mathrm{~kg} \mathrm{ha}^{-1}$ da fórmula NPK 08-28-16 na linha de plantio. No estádio fenológico V4 foi realizada a adubação de cobertura com $200 \mathrm{~kg} \mathrm{ha}^{-1}$ de uréia e $100 \mathrm{~kg} \mathrm{ha}^{-1}$ de $\mathrm{KCl}$ no estádio fenológico V2.

O controle de plantas daninhas foi realizado por meio de aplicação de herbicida em pós emergência com o ingrediente ativo Nicosulfuron, na dose de $16 \mathrm{~g}$ i.a. ha-1, e Atrazine, na dose de $1250 \mathrm{~g}$ i.a. ha ${ }^{-1}$, dez dias após a emergência das plântulas. 
Os tratamentos experimentais adotados foram: 1) híbrido simples HS4 derivado de planta dominante; 2) híbrido simples HS4 derivado de planta dominada; 3) híbrido triplo HT5 derivado de planta dominante; 4) híbrido triplo HT5 derivado de planta dominada; 5) híbrido duplo HD6 derivado de planta dominante; 6) híbrido duplo HD6 derivado de planta dominada.

\subsubsection{Avaliações experimentais}

\subsubsection{Determinação da altura da planta e da espiga}

A avaliação da altura da planta e da espiga foi feita no estádio fenológico R3 (grãos pastosos), medindo-se a inserção da última folha (folha bandeira) e da inserção da espiga no colmo até a superfície do solo. Fez-se a medição da $4^{a}, 5^{a}$ e $10^{\underline{a}}$ planta de cada linha, totalizando seis plantas em cada parcela, obtendo-se a média aritmética.

\subsubsection{Determinação do peso de 1000 sementes}

Foi feito o peso de 1000 sementes (P1000), obtido pela média da contagem e pesagem de oito repetições de 100 sementes. O resultado é expresso em gramas, conforme a Regras para Análise de Sementes - RAS (BRASIL, 2009).

\subsubsection{Avaliação da qualidade fisiológica das sementes}

Para a avaliação fisiológica das sementes foram feitos os testes de germinação e de envelhecimento acelerado no Laboratório de Análise de Sementes da Limagrain ${ }^{\circledR}$, em Goianésia-GO.

a) Teste de germinação

O teste de germinação foi realizado com quatro repetições de 50 sementes por tratamento, em rolo de papel toalha, tipo Germitest, embebido em água na quantidade de 2,5 vezes o peso do substrato seco, acondicionado em sacos plásticos. Foram mantidos em câmara de germinação, à temperatura de $25 \stackrel{\circ}{ } \mathrm{C}$, sendo a contagem das plântulas normais feitas no quinto dia, seguindo-se os critérios estabelecidos nas Regras para Análise de Sementes (BRASIL, 2009). Os resultados foram expressos em porcentagem média de plântulas normais. 
b) Teste de envelhecimento acelerado

As sementes foram distribuídas em camada única sobre uma tela metálica que foi encaixada dentro de uma caixa plástica para germinação $(11,0 \times 11,0 \times 3,5 \mathrm{~cm})$, contendo $40 \mathrm{~mL}$ de água destilada no fundo e foi mantida em câmara de germinação, a $42{ }^{\circ} \mathrm{C}$ por $48 \mathrm{~h}$ (MARCOS FILHO, 1999). Após o período de envelhecimento, as sementes foram submetidas ao teste de germinação, sendo a contagem de plântulas normais realizada no quinto dia (BRASIL, 2009).

\subsubsection{Avaliação da produtividade}

Foi obtida a produtividade de cada parcela através da colheita manual das espigas no estádio fenológico R6, quando os grãos já atingiram a maturidade fisiológica, com um teor de água de 30 a 32. Então, as espigas foram secas em câmaras de secagem de milho em espiga, na Unidade de Beneficiamento de Sementes da empresa Sempre Sementes, em Santa Helena de Goiás-GO, até atingirem o teor de água de $12 \%$ da base úmida. Foi feita a debulha das espigas e obtido os pesos dos grãos de cada parcela.

\subsubsection{Delineamento e análise estatística}

O delineamento experimental adotado foi em esquema fatorial 3 (híbridos) $\times 2$ (tipo de planta de origem da semente), com três repetições. As médias foram comparadas pelo teste de Tukey, em nível de $5 \%$ de probabilidade. Os dados foram analisados pelo software "ASSISTAT", versão 7.7 beta (SILVA, 2014). 


\section{RESULTADOS E DISCUSSÃO}

\subsection{Experimento 1}

A qualidade fisiológica das sementes não mostrou diferença significativa tanto para a análise de germinação quanto para o teste de envelhecimento acelerado (EA), indicando que não há interferência dos tratamentos aplicados na germinação e vigor das sementes (Tabelas 1 e 2).

Resultados semelhantes foram obtidos por Wilhelm et al. (1995) e Hunter e Tekrony (1988), os quais não encontraram influência da remoção de folhas no despendoamento não influenciou a germinação das sementes, sugerindo que a qualidade fisiológica das sementes está mais relacionada com a maturidade na colheita que com a desfolha.

Por outro ladro, resultados divergentes foram obtidos por Fancelli (1988), que verificou redução da porcentagem de germinação com a remoção de cinco folhas superiores de plantas de milho.

Tabela 1. Valores médios de germinação dos genótipos submetidos a diferentes níveis de retiradas de folhas no despendoamento.

\begin{tabular}{cccc}
\hline \hline & \multicolumn{3}{c}{ GERMINAÇÃO (\%) } \\
\cline { 2 - 4 } TRATAMENTO ${ }^{(1)}$ & $\mathrm{L} 1$ & $\mathrm{~L} 2$ & $\mathrm{HS} 3$ \\
\hline 1 & $96 \mathrm{a}$ & $97 \mathrm{a}$ & $98 \mathrm{a}$ \\
2 & $96 \mathrm{a}$ & $97 \mathrm{a}$ & $98 \mathrm{a}$ \\
3 & $96 \mathrm{a}$ & $97 \mathrm{a}$ & $98 \mathrm{a}$ \\
4 & $98 \mathrm{a}$ & $96 \mathrm{a}$ & $100 \mathrm{a}$ \\
5 & $98 \mathrm{a}$ & $98 \mathrm{a}$ & $98 \mathrm{a}$ \\
6 & $98 \mathrm{a}$ & $98 \mathrm{a}$ & $99 \mathrm{a}$ \\
\hline Teste F - Tratamentos & $0,53 \mathrm{~ns}$ & $0,45 \mathrm{~ns}$ & $1,10 \mathrm{~ns}$ \\
Teste F - Blocos & $0,21 \mathrm{~ns}$ & $1,14 \mathrm{~ns}$ & $0,23 \mathrm{~ns}$ \\
DMS (Tukey 5\%) & 6,42 & 5,44 & 3,65 \\
CV (\%) & 2,33 & 1,97 & 1,31 \\
\hline \hline
\end{tabular}

(1) Tratamento: 1 (sem folhas acima da espiga); 2 (1 folha acima da espiga); 3 (2 folhas acima da espiga); 4 (3 folhas acima da espiga); 5 (4 folhas acima da espiga); 6 (apenas inflorescência masculina retirada). ns Valor não significativo a $1 \%$ de probabilidade.

Médias seguidas pela mesma letra não diferem entre si, pelo teste de Tukey, a $5 \%$ de probabilidade. 
Houve diferença significativa entre os tratamentos para o peso de mil sementes (P1000) a $1 \%$ de probabilidade. A retirada de folhas reduziu o peso de sementes. Em ambas as linhagens e no híbrido simples o maior peso foi obtido no tratamento sem a retirada de folhas. Em todos os genótipos o maior P1000 sementes foi o tratamento sem a retirada de folhas e o menor na retirada de todas as folhas acima da espiga (Tabela 3).

Resultado semelhante tiveram Dungan e Woodworth (1939) que observaram redução progressiva no peso de sementes semelhante à redução na produção de grãos com o aumento do número de folhas removidas com o pendão.

Contudo, Fancelli (1988) não detectou diferença significativa no peso de 1000 sementes quando a desfolha ocorreu no florescimento, no estádio fenológico R1, comparado com plantas que não foram submetidos à desfolha.

Tabela 2. Valores médios de envelhecimento acelerado dos genótipos submetidos a diferentes níveis de retiradas de folhas no despendoamento.

\begin{tabular}{cccc}
\hline \hline & \multicolumn{3}{c}{ ENVELHECIMENTO ACELERADO (\%) } \\
\cline { 2 - 4 } TRATAMENTO (1) & L1 & L2 & HS3 \\
\hline 1 & $91 \mathrm{a}$ & $88 \mathrm{a}$ & $85 \mathrm{a}$ \\
2 & $91 \mathrm{a}$ & $90 \mathrm{a}$ & $84 \mathrm{a}$ \\
3 & $89 \mathrm{a}$ & $91 \mathrm{a}$ & $84 \mathrm{a}$ \\
4 & $89 \mathrm{a}$ & $90 \mathrm{a}$ & $88 \mathrm{a}$ \\
5 & $91 \mathrm{a}$ & $91 \mathrm{a}$ & $85 \mathrm{a}$ \\
6 & $89 \mathrm{a}$ & $91 \mathrm{a}$ & $87 \mathrm{a}$ \\
\hline Teste F - Tratamentos & $0,99 \mathrm{~ns}$ & $0,77^{\mathrm{ns}}$ & $0,92 \mathrm{~ns}$ \\
Teste F - Blocos & $0,01^{*}$ & $0,16 \mathrm{~ns}$ & $0,46 \mathrm{~ns}$ \\
DMS (Tukey 5\%) & 5,57 & 6,72 & 7,83 \\
CV (\%) & 2,18 & 2,63 & 3,23 \\
\hline \hline
\end{tabular}

(1) Tratamento: 1 (sem folhas acima da espiga); 2 (1 folha acima da espiga); 3 (2 folhas acima da espiga); 4 (3 folhas acima da espiga); 5 (4 folhas acima da espiga); 6 (apenas inflorescência masculina retirada).

* Valor significativo a $5 \%$ de probabilidade; ns Valor não significativo a $5 \%$ de probabilidade.

Médias seguidas pela mesma letra não diferem entre si, pelo teste de Tukey, a 5\% de probabilidade.

Hunter et al. (1973) observaram que a remoção de duas a três folhas pelo despendoamento diminuiu significativamente o peso de 1000 sementes em linhagens precoces e em apenas uma linhagem tardia. Este foi o componente de produção que 
mais afetou a produção de grãos, tendo causado, nas linhagens precoces, uma redução de $55 \%$.

Corroborando com os resultados deste trabalho o peso sementes e o número de sementes por espiga são os componentes que mais influenciaram no rendimento de grãos, conforme relatado por Wilhelm et al. (1995).

Tabela 3. Valores médios de P1000 sementes dos genótipos submetidos a diferentes níveis de retiradas de folhas no despendoamento.

\begin{tabular}{|c|c|c|c|}
\hline \multirow[b]{2}{*}{ TRATAMENTO (1) } & \multicolumn{3}{|c|}{ P1000 (g) } \\
\hline & $\mathrm{L} 1$ & $\mathrm{~L} 2$ & HS3 \\
\hline 1 & $292,78 \quad c$ & $220,43 \quad d$ & $232,19 \quad d$ \\
\hline 2 & $297,53 \mathrm{bc}$ & $221,33 \mathrm{~cd}$ & $236,56 \mathrm{~cd}$ \\
\hline 3 & $304,20 a b$ & $230,28 \mathrm{bc}$ & 241,73 bc \\
\hline 4 & $304,85 a b$ & $230,82 a b c$ & $245,10 a b c$ \\
\hline 5 & $308,64 \mathrm{a}$ & $235,76 a b$ & $247,47 a b$ \\
\hline 6 & $312,20 \mathrm{a}$ & $240,48 \mathrm{a}$ & $252,20 \mathrm{a}$ \\
\hline Teste F - Tratamentos & $14,63 * *$ & $15,98^{* *}$ & $15,55^{* *}$ \\
\hline Teste F - Blocos & $0,47^{n s}$ & $0,86 \mathrm{~ns}$ & $1,45^{\mathrm{ns}}$ \\
\hline DMS (Tukey 5\%) & 9,17 & 9,68 & 9,11 \\
\hline CV (\%) & 1,07 & 1,49 & 1,33 \\
\hline
\end{tabular}

(1) Tratamento: 1 (sem folhas acima da espiga); 2 (1 folha acima da espiga); 3 (2 folhas acima da espiga); 4 (3 folhas acima da espiga); 5 (4 folhas acima da espiga); 6 (apenas inflorescência masculina retirada).

${ }_{* \star}$ Valor significativo a $1 \%$ de probabilidade; ns Valor não significativo a $5 \%$ de probabilidade.

Médias seguidas pela mesma letra não diferem entre si, pelo teste de Tukey, a 5\% de probabilidade.

A análise de variância dos valores referentes a produtividade dos três genótipos foi significativa (Tabela 4). O resultado de produtividade das linhagens e do híbrido simples foi afetado pelo número de folhas retiradas ao nível de $1 \%$ de probabilidade, sendo a melhor produtividade com apenas a inflorescência retirada e o pior resultado de produtividade sem a presença de folhas acima da espiga. Na linhagem L1 a retirada de todas as folhas acima da espiga reduziu em $21,7 \%$, e na linhagem L2 em 16,9\%. No híbrido simples HS3 a perda foi de 5,1\% mostrando que as linhagens apresentaram-se mais sensíveis a retirada de folhas quando comparadas ao híbrido simples. A produtividade está relacionada ao número de folhas retiradas, quanto maior o número de folhas retiradas menor será a produtividade. 
De forma semelhante Wilhelm et al. (1995) obtiveram redução na produtividade quando da remoção do pendão mais quatro folhas. Conforme observado por Frascaroli et al. (2005), a desfolha diminui a matéria seca de grãos na colheita, sendo as perdas maiores quando a desfolha se realizou nos estádios iniciais de desenvolvimento dos grãos, como verificado nesse experimento.

Tabela 4. Valores médios de produtividade dos genótipos submetidos a diferentes níveis de retiradas de folhas no despendoamento.

\begin{tabular}{|c|c|c|c|}
\hline \multirow[b]{2}{*}{ TRATAMENTO (1) } & \multicolumn{3}{|c|}{ PRODUTIVIDADE (kg ha $\left.{ }^{-1}\right)$} \\
\hline & $\mathrm{L} 1$ & $\mathrm{~L} 2$ & HS3 \\
\hline 1 & $2.518 \mathrm{c}$ & $2.872 \quad d$ & $6.064 \mathrm{c}$ \\
\hline 2 & $2.649 \mathrm{bc}$ & $2.965 \mathrm{~cd}$ & $6.096 \mathrm{bc}$ \\
\hline 3 & $2.918 a b c$ & $3.140 \mathrm{bc}$ & $6.231 \mathrm{ab}$ \\
\hline 4 & $3.077 \mathrm{a}$ & $3.232 \mathrm{ab}$ & $6.265 \mathrm{a}$ \\
\hline 5 & $3.033 a b$ & $3.303 a b$ & $6.289 \mathrm{a}$ \\
\hline 6 & $3.176 \mathrm{a}$ & $3.457 \mathrm{a}$ & $6.388 \mathrm{a}$ \\
\hline Teste F - Tratamentos & 9,12 ** & 16,27 ** & 13,22 ** \\
\hline Teste F - Blocos & $0,01^{n s}$ & $1,18^{\mathrm{ns}}$ & $0,78^{n s}$ \\
\hline DMS (Tukey 5\%) & 420,15 & 264,05 & 165,30 \\
\hline CV (\%) & 5,12 & 2,95 & 0,94 \\
\hline
\end{tabular}




\subsection{Experimento 2}

As sementes coletadas de plantas dominadas e de plantas dominantes dos campos de produção de cada genótipo apresentaram os resultados da avaliação fisiológica de acordo com a Tabela 5.

Tabela 5. Valores médios das sementes de milho obtidas do campo de produção de sementes das plantas dominadas e dominantes para o teste de germinação (GERM) e o teste de envelhecimento acelerado (EA).

\begin{tabular}{ccccccc}
\hline & \multicolumn{2}{c}{$\mathrm{HS4}^{(1)}$} & \multicolumn{2}{c}{$\mathrm{HT5}$} & \multicolumn{2}{c}{$\mathrm{HD6}$} \\
\cline { 2 - 7 } & GERM (\%) & EA (\%) & GERM (\%) & EA (\%) & GERM (\%) & EA (\%) \\
\hline $\mathrm{A}^{(2)}$ & $93 \mathrm{~b}$ & $78 \mathrm{~b}$ & $91 \mathrm{~b}$ & $73 \mathrm{~b}$ & $92 \mathrm{~b}$ & $81 \mathrm{~b}$ \\
$\mathrm{~B}$ & $97 \mathrm{a}$ & $88 \mathrm{a}$ & $96 \mathrm{a}$ & $82 \mathrm{a}$ & $97 \mathrm{a}$ & $86 \mathrm{a}$ \\
\hline Teste F & $13,6^{* *}$ & $62,4^{* *}$ & $42,8^{* *}$ & $148,8^{* *}$ & $44,6^{* *}$ & $57,4^{* *}$ \\
DMS & 2,3 & 2,7 & 1,7 & 1,7 & 1,5 & 1,3 \\
CV (\%) & 2,27 & 3,06 & 1,67 & 2,04 & 1,47 & 1,47
\end{tabular}

(1) Sementes de origem F1 do híbrido simples HS4, híbrido triplo HT5 e híbrido duplo HD6.

(2) A (Sementes de Plantas Dominadas), B (Sementes de Plantas Dominantes).

${ }_{* *}$ Valor significativo a $1 \%$ de probabilidade.

Médias seguidas pela mesma letra na coluna não diferem entre si, pelo teste de Tukey, a 5\% de probabilidade.

As sementes oriundas de plantas dominadas foram diferentes significativamente das sementes de plantas dominantes quanto à qualidade fisiológica a $1 \%$ de probabilidade. $\mathrm{Na}$ avaliação da germinação e do envelhecimento acelerado as sementes oriundas de plantas dominadas tiveram resultados inferiores as sementes de plantas dominantes $(p<0,05)$ (Tabela 5).

O peso de mil sementes foi significativamente diferente ao nível de $1 \%$ de probabilidade (Tabela 6). Nos três genótipos avaliados, o peso das sementes de plantas dominantes foi superior ao das sementes de plantas dominadas.

O menor peso das sementes de plantas dominadas explica a menor qualidade fisiológica das sementes de plantas dominadas, pois um dos fatores que afeta o vigor é o tamanho e densidade dos grãos, de acordo com Carvalho e Nakagawa (2000).

$\mathrm{Na}$ análise de variância não houve interação significativa entre genótipos e plantas de origem da semente, tanto na altura de espiga como na altura de plantas (Tabela 7). 
$\mathrm{Na}$ altura de espiga e altura de plantas para a estatística do efeito simples, houve diferença significativa $(p \leq 0,01)$ entre os genótipos, pois cada híbrido tem as suas características fenotípicas bem definidas, como a arquitetura de folhas (Tabela 7).

Tabela 6. Valores médios do peso de 1000 sementes de milho obtidas do campo de produção de sementes das plantas dominadas e dominantes.

\begin{tabular}{cccc}
\hline \hline & HS4 (1) & HT5 & HD6 \\
\cline { 2 - 4 } & & P1000 $(\mathrm{g})$ & \\
\hline $\mathrm{A}^{(2)}$ & $235,27 \mathrm{~b}$ & $219,70 \mathrm{~b}$ & $220,76 \mathrm{~b}$ \\
$\mathrm{~B}$ & $274,71 \mathrm{a}$ & $237,46 \mathrm{a}$ & $240,55 \mathrm{a}$ \\
\hline Teste F & $1568,0^{* *}$ & $975,8 * *$ & 150,1 ** \\
DMS & 2,13 & 1,22 & 3,46 \\
CV (\%) & 0,78 & 0,50 & 1,40
\end{tabular}

(1) Sementes de origem F1 do híbrido simples HS4, híbrido triplo HT5 e híbrido duplo HD6.

(2) A (Sementes de Plantas Dominadas), B (Sementes de Plantas Dominantes).

** Valor significativo a $1 \%$ de probabilidade.

Médias seguidas pela mesma letra na coluna não diferem entre si, pelo teste de Tukey, a 5\% de probabilidade.

A estatística do efeito simples para tipo de planta apresentou diferença significativa, sendo a $5 \%$ de probabilidade para altura de espiga e a $1 \%$ de probabilidade para altura de planta. Isto é explicado pela superioridade no vigor das sementes de plantas dominantes em relação a plantas dominadas.

Nesse contexto, Pommel et al. (2002) descreveram que plantas emergidas tardiamente e rodeadas por plantas emersas apresentaram atraso na expansão foliar e no crescimento em altura de plantas, o que corrobora com os resultados deste trabalho.

Segundo Sangoi et al. (2010), em lavouras com emergência uniforme, as plantas são mais homogêneas quanto à sua arquitetura, minimizando a competição intraespecífica. 
Tabela 7. Valores médios da altura de plantas (AP) e altura de espigas (AE) em m, e ocorrência de plantas dominadas (PD) quanto ao tipo de planta da origem da sementes e diferentes genótipos de milho.

TRATAMENTO AE AP $\quad$ PD

\begin{tabular}{lccc}
\hline HS4 & $-\cdot, 42 \mathrm{~b}$ & $2,38 \mathrm{~b}$ & $1,11 \mathrm{a}$ \\
HT5 & $1,63 \mathrm{a}$ & $2,73 \mathrm{a}$ & $1,45 \mathrm{a}$ \\
HD6 & $1,40 \mathrm{~b}$ & $2,38 \mathrm{~b}$ & $1,25 \mathrm{a}$ \\
\hline Teste F - Genótipo & $50,85^{\star *}$ & $27,79^{\star *}$ & $0,28^{\text {ns }}$ \\
DMS (5\%) & 0,07 & 0,09 & 1,25 \\
\hline Sementes de Plantas Dominantes & $1,52 \mathrm{a}$ & $2,55 \mathrm{a}$ & $0,47 \mathrm{~b}$ \\
Sementes de Plantas Dominadas & $1,46 \mathrm{~b}$ & $2,45 \mathrm{~b}$ & $2,07 \mathrm{a}$ \\
\hline Teste F - Planta & $9,47^{*}$ & $11,11^{\star *}$ & $18,51^{* *}$ \\
DMS (5\%) & 0,05 & 0,06 & 0,83 \\
\hline Teste F - int. (Genótipo x Planta) & $0,40^{\text {ns }}$ & $1,01^{\text {ns }}$ & $2,97^{\text {ns }}$ \\
Teste F - Blocos & $1,30^{\text {ns }}$ & $1,24^{\text {ns }}$ & $1,34^{\text {ns }}$ \\
CV (\%) & 2,88 & 2,46 & 62,09 \\
\hline
\end{tabular}

Médias seguidas pela mesma letra na coluna não diferem entre si pelo teste de Tukey a 5\%.

ns Valores não significativos; * valores significativos a $5 \% \mathrm{e}^{* *}$ valores significativos a $1 \%$ de probabilidade pelo teste $\mathrm{F}$.

Não foi significativa a interação entre genótipos e plantas de origem na ocorrência de plantas caracterizadas como dominadas. Desta forma avaliou-se os efeitos simples para genótipos e plantas (dominantes e dominadas), sendo que para genótipos não houve diferença significativa indicando a ocorrência igual de plantas dominadas. Para origem de sementes de plantas dominadas a interação foi significativa $(p<0,01)$ indicando que sementes de plantas dominadas originam $77,3 \%$ a mais de plantas dominadas. A competição intraespecífica por luz entre plantas de sementes com menor vigor proporciona uma maior ocorrência de plantas dominadas (Tabela 7).

A interação do genótipo com plantas de origem não mostrou efeito para produtividade. O genótipo com melhor produtividade foi o híbrido simples HS4 enquanto que a menor produtividade observada foi do HT5, independente da origem 
da semente. A produtividade de plantas dominantes diferiu estatisticamente das sementes de plantas dominadas superadas em 12,3\% (Tabela 8 ).

Tabela 8. Valores médios da produtividade, quanto ao tipo de planta da origem da sementes e diferentes genótipos de milho.

TRATAMENTO

\begin{tabular}{lc}
\hline HS4 & $\left(\mathrm{kg} \mathrm{ha}^{-1}\right)$ \\
HT5 & $9722,83 \mathrm{a}$ \\
HD6 & $7060,00 \mathrm{~b}$ \\
\hline Teste F (Genótipos) & $8370,66 \mathrm{~b}$ \\
DMS (5\%) & $13,02^{\star \star}$ \\
\hline Sementes Plantas Dominantes & 1431,36 \\
Sementes Plantas Dominadas & $8935,88 \mathrm{a}$ \\
\hline Teste F - Plantas & $7833,11 \mathrm{~b}$ \\
DMS (5\%) & $6,70^{\star \star}$ \\
\hline Teste F - interação Genótipo x Planta & 948,81 \\
Teste F - Blocos & $0,26^{\mathrm{ns}}$ \\
CV (\%) & $2,16^{\mathrm{ns}}$ \\
\hline \hline
\end{tabular}

Médias seguidas pela mesma letra na coluna não diferem entre si pelo teste de Tukey a 5\%.

ns Valores não significativos; * valores significativos a $5 \% \mathrm{e}^{* *}$ valores significativos a $1 \%$ de probabilidade pelo teste $\mathrm{F}$.

As sementes de plantas dominadas foram de vigor mais baixo que as de plantas dominantes interferindo na produtividade. Houve maior ocorrência de plantas dominadas nas sementes oriundas de sementes de plantas dominadas. Os grãos produzidos por estas plantas têm menor peso específico e menor número de grãos vindo a refletir no rendimento.

Conforme relato de Pagano e Maddonni (2007) a variabilidade na emergência de plântulas de milho reduz a produtividade de grãos por área, sendo uma das causas, a baixa fertilidade das plântulas com emergência tardia. As plantas dominantes exibiram uma maior partição de biomassa para a espiga do que os indivíduos das plantas dominadas. As plantas dominantes apresentaram a mais alta taxa de crescimento da espiga e número de sementes por planta. 
Mondo et al. (2009) afirmaram que a homogeneidade do lote de sementes para vigor, mostrou-se fundamental para a obtenção de altas produtividades em campos de produção de milho, diminuindo a ocorrência de plantas dominadas, conforme observado neste trabalho.

O aumento da produtividade de grãos de milho foi relacionado à maximização da exploração dos fatores ambientais, que acontece de forma mais efetiva quando existe uniformidade entre plantas, proporcionando baixa competição intraespecífica, em milho, que mostrou-se altamente sensível a este tipo de competição (MADDONNI; OTEGUI, 2006). Esta observação é concordante com o que foi obtido neste trabalho.

$O$ vigor das sementes afeta o crescimento inicial de plantas, acarretando variabilidade de crescimento, por competição intraespecífica, resultando na menor capacidade competitiva das plantas dominadas, refletindo negativamente na produtividade, de acordo com o relatado por Mondo et al. (2012).

Ademais, o aumento da variação na emergência entre plantas dominantes e dominadas explica a variação do rendimento de grãos. No entanto, de forma isolada o componente que mais influenciou o rendimento foi o número de grãos por espiga, que apresentou diminuição com o aumento da variação entre a emergência das plantas (SCHENATTO et al., 2012). 


\section{CONCLUSÕES}

A retirada de folhas no despendoamento interfere negativamente no peso de sementes e na produtividade de milho semente.

A qualidade fisiológica das sementes não é afetada pela desfolha, enquanto as sementes de plantas dominadas apresentam menor germinação e vigor.

Sementes de plantas dominadas geram maior frequência de plantas dominadas.

A produtividade do milho quando se utiliza sementes de plantas dominantes é superior em relação às sementes de plantas dominadas. 


\section{REFERÊNCIAS}

ADÁMOLI, J.; MACEDO, J.; AZEVEDO, L.G.; NETTO, J.M. Caracterização da região dos Cerrados. In: GOEDERT, W.J. (Ed.). Solos dos Cerrados: tecnologias e estratégias de manejo. Planaltina: Embrapa-CPAC; São Paulo: NOBEL, 1987. p.3398.

ALDRICH, S.R.; SCOTT, W.O.; LENG, E.R. Modern corn production. 2.ed. Champaign: A \& L Publication, 1982. 371p.

BRASIL. Ministério da Agricultura, Pecuária e Abastecimento. Regras para análise de sementes. Brasília: SNAD/DNPV/CLAV, 2009. 399p.

CARVALHO, N.M.; NAKAGAWA, J. Sementes: ciência, tecnologia e produção. 4.ed. Jaboticabal: FUNEP, 2000. 588p.

CONAB. Acompanhamento da safra brasileira de grãos: safra 2014/15 - quinto levantamento de fevereiro. Brasília: CONAB, 2015. 116p.

CULY, M.D.; EDWARDS, C.R.; CORNELIUS, J.R. Row position effects within seed corn production fields on yield and quality of inbred corn. Journal Production Agriculture, v.4, p.373-376, 1991.

DUNGAN, G.H.; WOODWORTH, C.M. Loss resulting from pulling leaves with the tassels in detasseling corn. Journal of the America Society of Agronomy, Washington, v.31, p.872-875, 1939.

EGHAREVBA, P.N.; HORROCKS, R.D.; ZUBER, M.S. Dry matter accumulation in maize in response to defoliation. Agronomy Journal, v.68, p.40-43, 1976.

EMBRAPA. Sistema brasileiro de classificação de solos. Rio de Janeiro: Embrapa Solos. 2006.

EMBRAPA. Milho: história e arte. Revista Eletrônica Grão em Grão, Sete Lagoas, maio, 2008. Disponível em:< http://www.cnpms.embrapa.br/grao/7 edicao $>$. Acesso em: 02 mar. 2014.

FANCELI, A.L. Plantas alimentíceas: guia para aula, estudos e discussão. Centro Acadêmico "Luiz de Queiroz". Piracicaba: ESALQ/USP, 1986. 131p. 
FANCELLI, A.L. Influência do desfolhamento no desempenho de plantas e sementes de milho (Zea mays L.). 1988. 172 f. Tese (Doutorado em Fitotecnia) Escola Superior de Agricultura "Luiz de Queiroz", Universidade de São Paulo, Piracicaba, 1988.

FANCELLI, A. L.; DOURADO NETO, D. Ecofisiologia e fenologia. In: FANCELLI, A. L.; DOURADO NETO, D. (Eds). Produção de milho. Guaiba: Agropecuária, 2000. p. 21-54.

FORNASIERI-FILHO, D. A cultura do milho. Jaboticabal: FUNEP, 1992. 273 p.

FRASCAROLI, E.; CASARINI, E.; CONTI, S. Response of maize inbred lines to a defoliation treatment inducing tolerance to cold at germination. Euphytica, v.145, p.295-303, 2005.

HUNTER, R.B.; MORTIMORE, C.G.; KANNENBERG, L.W. Inbred maize performance following tassel and leaf removal. Agronomy Journal, v.65, p.471-472, 1973.

HUNTER, J.L.; TEKRONY, D.M. Seed maturation and vigor in corn (Zea mays L.) as influenced by defoliation. In: ANNUAL MEETING OF THE AMERICAN SOCIETY OF AGRONOMY, 80., 1988, Procedures... Anahein: American Society of Agronomy, 1988. $145 p$.

JUGENHEIMER, R.W. Production of hybrid seed: mechanical detas-seling. In: JUGENHEIMER, R.W. (Ed.). Corn: improvement, seed production and uses. New York: J. Wiley, 1976. p. 451-452.

KOMATUDA, A.S.; SANTOS, C.M.; SANTANA, D.G.; SOUZA, M.A.; BRITO, C.S. Influência de métodos de despendoamento na produtividade e na qualidade das sementes de milho. Revista Brasileira de Milho e Sorgo, v.5, n.3, p.359-368, 2006.

KÖPPEN, W.; GEIGER, R. Klimate der Erde. Gotha: Verlag Justus Perthes. 1928. Wall-map $150 \mathrm{~cm} \times 200 \mathrm{~cm}$.

LARCHER, W. Ecofisiologia vegetal. São Carlos: Rima Artes e Textos, 2000. 531p.

MADDONNI, G.A.; OTEGUI, M.E. Intra-specific competition in maize: early establishment of hierarchies among plants affects final kernel set. Field Crops Research, v.85, n.1, p.1-13, 2004.

MAGALHÃES, P.C.; DURÃES, F.O.M.; OLIVEIRA, A.C.; GAMA, E.E.G. Efeitos de diferentes técnicas de despendoamento na produção de milho. Scientia Agricola, Piracicaba, v.56, n.1, p.77-82, 1999. 
MARCOS FILHO, J. Teste de envelhecimento acelerado. In: KRZYZANOWSKI, F.C.; VIEIRA, R.D.; FRANÇA NETO, J.B. (Eds.). Vigor de sementes: conceitos e testes. Londrina: ABRATES, 1999. cap.3. p.1-24.

MCDONALD, M.B.; COPELAND, L.O. Seed production: principles and practices. In: MCDONALD, M.B.; COPELAND, L.O. Cereal seeds. New York: Chapman \& Hall, 1996. cap. 13, p. 200-201.

MEROTO JÚNIOR, A.; SANGOI, L.; ALMEIDA, M.L.; ENDER, M. A desuniformidade de emergência reduz o rendimento de grãos de milho. Ciência Rural, v.29, p.595$601,1999$.

MONDO, V.H.V. Vigor de sementes e desempenho de plantas na cultura do milho. 2009. 83 f. Tese (Doutor em Ciências) - Escola Superior de Agricultura Luiz de Queiroz, USP, Piracicaba, 2009.

MONDO, V.H.V.; CICERO, S.M.; DOURADO-NETO, D.; PUPIM, T.L.; DIAS, M.A.N. Vigor de sementes e desempenho de plantas de milho. Revista Brasileira de Sementes, v.34, n.1 p.143 - 155, 2012.

PAGANO, E.; CELA, S.; MADDONNI, G.A.; OTEGUI, M.E. Intra-specific competition in maize: ear development, flowering dynamics and kernel set of early-established plant hierarchies. Field Crops Research, v.102, p.198-209, 2007.

PAGANO, E.; MADDONNI, G.A. Intra-specific competition in maize: early established hierarchies differ in plant growth and biomass partitioning to the ear around silking. Field Crops Research, v.101, p.306-320, 2007.

PATERNIANI, E.; CAMPOS, M.S. Melhoramento do milho. In: BORÉM, A. (Org.). Melhoramento de espécies cultivadas. Viçosa: UFV, p. 429-485, 1999.

POMMEL, B.; MOURAUX, D.; CAPPELLEN, O.; LEDENT, J.F. Influence of delayed emergence and canopy skips on the growth and development of maize plants: a plant scale approach with CERES-Maize. European Journal of Agronomy, v.16, p.263277, 2002.

PRIOUL, J.L.; SCHWEBEL-DUGUÉ, N. Source-sink manipulations and carbohydrate metabolism in maize. Crop Science, v.32, p.751-756, 1992.

SANGOI, L.; SILVA, P.R.F.; ARGENTA, G. Estratégias de manejo do arranjo de plantas para aumentar o rendimento de grãos de milho. Lages: Graphel, 2010. $64 p$. 
SILVA, F.A.S. ASSISTAT versão 7.7 beta. Campina Grande: DEAG/CTRN/UFCG, 2014. (Homepage http://www.assistat.com).

SCHENATTO, D.E.; SANGOI, L.; SCHIMITT, A.; VIEIRA, J.; MOTA, M.R.; SILVA, L.M.M.; GIORDANI, W.; BONIATI, C.M.; MACHADO, G.C. Desuniformidade Temporal na Distribuição de Plantas na Linha de Semeadura e Rendimento de Grãos do Milho. In: XXIX CONGRESSO NACIONAL DE MILHO E SORGO, 2012, Águas de Lindóia. Resumos... p. 2002 a 2008.

TOLLENAAR, M.; AHMADZADEH, A.; LEE, E.A. Physiological basis of heterosis for grain yield in maize. Crop Science, v.44, p. 2086-2094, 2004.

VILLIERS, T.A. Ageing and longevity of seeds in field conditions. In: HEYDECKER, W. (Ed.). Seed ecology. London: The Pennsylvania State University Press, 1973. p.265288

WILHELM, W.W.; JONHNSON, B.E.; SCHEPERS, J.S. Yields, quality, and nitrogen use of inbred corn with varying numbers of leaves removed during detasseling. Crop Science, Madison, v.35, p.209-212, 1995. 